\title{
Higher Prevalence of Depressive Symptoms in Middle-Aged Men With Low Serum Cholesterol Levels
}

Paul H. A. Steegmans, MD, Arno W. Hoes, MD, PhD, Annette A. A. Bak, MD, PhD, Emiel van der Does, MD, PhD, and Diederick E. Grobbee, MD, PhD

\begin{abstract}
Objective: Investigators from several studies have reported a positive relationship between low cholesterol levels and death due to violent causes (eg, suicide and accidents), possibly mediated by depressive symptoms, aggression or hostility, or impulsivity. We set out to establish whether middle-aged men with chronically low cholesterol levels ( $\leq 4.5 \mathrm{mmol} / \mathrm{liter}$ ) have a higher risk of having depressive symptoms, according to scores on the Beck Depression Inventory, compared with a reference group of men with cholesterol levels between 6 and $7 \mathrm{mmol} / \mathrm{liter}$. A similar comparison was also made for measures of anger, hostility, and impulsivity. Methods: Cholesterol measurements were obtained as part of a population-based cholesterol screening study in 1990-1991. These levels were remeasured in 1993-1994. Only those whose cholesterol level remained in the same range were included in the study. Depressive symptoms were assessed by using the Beck Depression Inventory; anger, by questionnaires based on the Spielberger Anger Expression Scale and State-Trait Anger Scale; hostility, by the Buss-Durkee Hostility Inventory; and impulsivity, by the Eysenck and Eysenck Impulsivity Questionnaire. Results: Men with chronically low cholesterol levels showed a consistently higher risk of having depressive symptoms (Beck Depression Inventory score $\geq 15$ or $\geq 17$ ) than the reference group, even after adjusting for age, energy intake, alcohol use, and presence of chronic diseases. No differences in anger, hostility, and impulsivity were observed between the two groups. Conclusions: Men with a lower cholesterol level ( $\leq 4.5 \mathrm{mmol} / \mathrm{liter})$ have a higher prevalence of depressive symptoms than those with a cholesterol level between 6 and $7 \mathrm{mmol} / \mathrm{liter}$. These data may be important in the ongoing debate on the putative association between low cholesterol levels and violent death. Key words: depressive symptoms, serum cholesterol, men, hostility, impulsivity, anger.
\end{abstract}

BDHI $=$ Buss-Durkee Hostility Inventory; BDI $=$ Beck Depression Inventory; CES-D = Centers for Epidemiologic Studies’ Depression Scale; CI = confidence interval; IMP = Impulsivity Questionnaire; RR = relative risk; SAQ = Self-Analysis Questionnaire; SECQ = Self-Expression and -Control Questionnaire.

\section{INTRODUCTION}

A number of investigators have reported on the relationship between chronically low cholesterol levels and death due to violent causes, notably suicide (1-6). It has been suggested that low cholesterol levels could lead to depression or increased risk of suicide, mediated by changes in serotonin metabolism (7-10). This mechanism would also be responsible for the association between low cholesterol levels and increased aggression observed in several human and animal stud-

From the Departments of Epidemiology and Biostatistics (P.H.A.S., A.W.H., A.A.A.B., D.E.G.) and General Practice (P.H.A.S., A.W.H., E.V.), Erasmus University Medical School, Rotterdam; and the Julius Center for Patient-Oriented Research (A.W.H., A.A.A.B., D.E.G.), Academic Hospital/Utrecht University, Utrecht, The Netherlands.

Address reprint requests to: Professor Diederick E. Grobbee, Julius Center for Patient-Oriented Research, University Medical Center Utrecht, P.O. Box 80035, 3508 TA Utrecht, The Netherlands. Email: D.E.GROBBEE@jc.azu.NL

Received for publication July 21, 1998; revision received August 24, 1999. ies (11-17). Impulsivity has also been associated with suicide and aggression or hostility (18-20), but its relationship with low cholesterol levels has not been addressed in previous studies.

So far, two cross-sectional studies have addressed the association between cholesterol levels and depressive symptoms in older men, and both found a higher prevalence of depressive symptoms among those with chronically low (ie, not lowered) cholesterol levels $(21,22)$. In a number of short-term experimental studies among hypercholesterolemic patients, in which cholesterol levels were lowered by drugs or diet, a higher mortality due to violent causes was observed in the intervention group (23-26). These findings, however, could not be confirmed in several other studies $(27,28)$. It has been suggested that depressive symptoms or hostility induced by lowering the cholesterol level could be involved in this unexpected phenomenon $(29,30)$. In a nonrandomized study comparing subjects changing to a low-fat, high-carbohydrate diet with those adhering to a traditional high-fat diet, subjects changing to a low-fat, high-carbohydrate diet had a significantly lower plasma cholesterol level and a lower rate of depression. However, statistically significant associations between changes in plasma cholesterol and changes in depression or aggressive hostility were not observed (31). No studies in which the relationship between chronically low cholesterol levels and hostility or impulsivity was investigated have been published.

To study the relationship between cholesterol level and depressive symptoms, anger, hostility, and impul- 
sivity, we compared two groups of middle-aged, nonhospitalized men, one with chronically low cholesterol levels ( $\leq 4.5 \mathrm{mmol} / \mathrm{liter}$ ) and one with cholesterol levels between 6 and $7 \mathrm{mmol} / \mathrm{liter}$.

\section{METHODS}

A cholesterol screening survey was conducted among 30,359 men, aged 40 to 70 years, in the Rotterdam, Netherlands, metropolitan area in 1990-1991. Nonfasting blood samples were obtained, and cholesterol level was measured enzymatically (32). A random sample of 310 men with a total serum cholesterol level below the fifth centile of the cholesterol distribution $(\leq 4.5 \mathrm{mmol} / \mathrm{liter})$ were invited to have a second cholesterol measurement in 1993-1994 unless they used antidiabetic medication or cholesterol-lowering drugs or had kidney disease, thyroid disease, or cancer. A second cholesterol measurement was obtained in a total of 190 subjects. In $130(68 \%)$ of these subjects, the cholesterol level was again $\leq 4.5$ $\mathrm{mmol} / \mathrm{liter}$, and these subjects were placed in the low cholesterol group. In addition, a sample of 401 men with initial cholesterol levels between the 35th and 75th centiles of the cholesterol distribution (between 6 and $7 \mathrm{mmol} / \mathrm{liter}$ ) were invited for a second cholesterol measurement, and blood was drawn in 235 of those invited. The 130 (55\%) subjects with a cholesterol level between 6 and $7 \mathrm{mmol} /$ liter at the second measurement made up the reference group. In both the low cholesterol and reference groups, refusal to visit the research center for the second cholesterol measurement was attributed to the time required for participation in the vast majority of subjects. The fasting blood sample was also used to measure triglyceride level. Subjects from the reference group were matched for age ( \pm 5 years) and socioeconomic background (as indicated by postal code) to those in the low cholesterol group. Participants from both groups completed a questionnaire requesting information on medication use and chronic diseases and a semiquantitative food frequency questionnaire (33) and were invited to visit the research center. At the center, all questionnaires were checked, a medical history was obtained, and a physical examination was conducted by a physician. In addition, subjects were asked about any changes in appetite over the last year and weight loss $(>5 \%$ of usual body weight) in the previous 6 months. Alcohol use was assessed by asking subjects about the number of alcoholic drinks consumed daily, and this number was multiplied by a standard mean alcohol content per drink. Specific questions were asked about the prevalence of chronic diseases, notably pulmonary, gastrointestinal, and cardiovascular disorders.

All participants filled out five psychological questionnaires (Table 2): the 21-item BDI (34); a 40-item SECQ (35), based on the Spielberger Anger Expression Scale (36); the 20-item SAQ (37), based on the Spielberger State-Trait Anger Scale; the 75-item BDHI (38); and the 25-item IMP, based on the work of Eysenck and Eysenck (39). For the BDI, two cutoff points, determined on the basis of previous studies, were used to define depressive symptoms: $\geq 15$ and $\geq 17$ (40). Two distinct factors of the BDHI were studied, the experiential (Resentment and Suspicion subscales) and the expressive (Assault, Verbal and Indirect Hostility, and Irritability subscales) (41-43).

\section{Data Analysis}

Mean scores on the psychological questionnaires in the two groups were compared by applying the Mann-Whitney $U$ test because of their nonnormal distribution. Differences of categorical variables between the cholesterol groups were tested with the $\chi^{2}$ test. For questionnaire scores with established clinical cutoff points, a dichotomous variable was created. A multivariate logistic regression model was used, with the dichotomized questionnaire score as the dependent variable, to adjust for potential confounders, such as weight loss, alcohol use, and chronic diseases.

Results of all analyses are expressed as means or odds ratios (as approximations of RRs) with 95\% CIs. Associations of serum triglyceride levels with scores on psychological questionnaires were also investigated. In the analysis, the logarithm of triglyceride levels was used to obtain a normal distribution.

\section{RESULTS}

Table 1 shows relevant general characteristics of the study population. In total, 130 men were included in

TABLE 1. General Characteristics of Men With a Low Cholesterol Level ( $\leq 4.5 \mathrm{mmol} / \mathrm{liter}$ ) and a Reference Group of Men With a Cholesterol Level Between 6 and 7 mmol/liter

\begin{tabular}{|c|c|c|c|c|c|}
\hline \multirow{2}{*}{ Characteristic } & \multicolumn{2}{|c|}{$\begin{array}{l}\text { Low Cholesterol Group } \\
\qquad(\mathrm{N}=126)\end{array}$} & \multicolumn{2}{|c|}{$\begin{array}{l}\text { Reference Group } \\
\qquad(N=129)\end{array}$} & \multirow{2}{*}{$\mathrm{p}^{\mathrm{a}}$} \\
\hline & Mean & SEM & Mean & SEM & \\
\hline Age, years & 55.1 & 0.8 & 55.6 & 0.8 & .69 \\
\hline Height, cm & 176.8 & 0.6 & 176.2 & 0.6 & .52 \\
\hline Weight, kg & 76.4 & 1.1 & 77.4 & 0.9 & .46 \\
\hline Body mass index, $\mathrm{kg} / \mathrm{m}^{2}$ & 24.4 & 0.3 & 24.9 & 0.3 & .15 \\
\hline Diastolic blood pressure, $\mathrm{mm} \mathrm{Hg}$ & 84.7 & 1.0 & 85.7 & 1.0 & .47 \\
\hline Systolic blood pressure, $\mathrm{mm} \mathrm{Hg}$ & 134.9 & 1.7 & 136.5 & 1.5 & .48 \\
\hline Serum cholesterol, $\mathrm{mmol} / \mathrm{liter}$ & 3.8 & 0.04 & 6.6 & 0.04 & $b$ \\
\hline Smoking, \% & 37 & & 45 & & .22 \\
\hline Caloric intake, kJ/day & 11,450 & 300 & 10,970 & 280 & .23 \\
\hline Alcohol intake, g/day & 14.7 & 1.7 & 23.4 & 2.3 & .003 \\
\hline Fat intake, g/day & 112.1 & 3.9 & 105.4 & 3.5 & .20 \\
\hline Recent weight loss, \% & 6.2 & & 4.7 & & .58 \\
\hline Family history of depression or suicide, $\%$ & 7.1 & & 8.5 & & .68 \\
\hline
\end{tabular}

\footnotetext{
${ }^{a}$ Two sided.

${ }^{b}$ Selection of groups based on cholesterol level.
} 
each group. Data from psychological questionnaires were not available from four participants in the low cholesterol group and from one in the reference group, mainly because of language problems. Alcohol intake in the low cholesterol group was considerably lower than in the reference group. No significant differences in medication use were observed.

The distribution of BDI scores is shown in Figure 1. The relative risk of having depressive symptoms according to the BDI is shown in Figure 2 for various cutoff points to define depressive symptoms. Twelve men in the low cholesterol group and three in the reference group had scores of $\geq 15$ or higher, and eight and one, respectively, had scores of 17 or higher. When applying the cutoff points of 15 or 17 to classify severe depressive symptoms, the RR of having depressive symptoms for those in the low cholesterol group and those in the reference group was 4.4 (95\%CI, 1.216.1) and 8.7 (95\%CI, 1.1-70.3), respectively. After adjustment for differences in age, recent weight loss, alcohol use, total energy intake, body mass index, and presence of chronic diseases, the RRs were 7.0 (95\%CI, 1.7-29.5) and 17.5 (95\%CI, 1.4-224), respectively.

In this multivariate analysis, both recent weight loss exceeding $5 \%(R R=6.8$ and 18.4 for BDI cutoff points of 15 and 17, respectively) and lower caloric intake (per $1000 \mathrm{~kJ}$; RR = 1.4 and 2.2 for BDI cutoff points of 15 and 17 , respectively) were associated with an increased risk of depressive symptoms.

The mean and median scores on the SECQ and SAQ, subscales of the BDHI, and the IMP of the two groups are shown in Table 2. Results for these scales were similar in the low cholesterol and reference groups, as was the distribution of scores. In addition, categoriza-

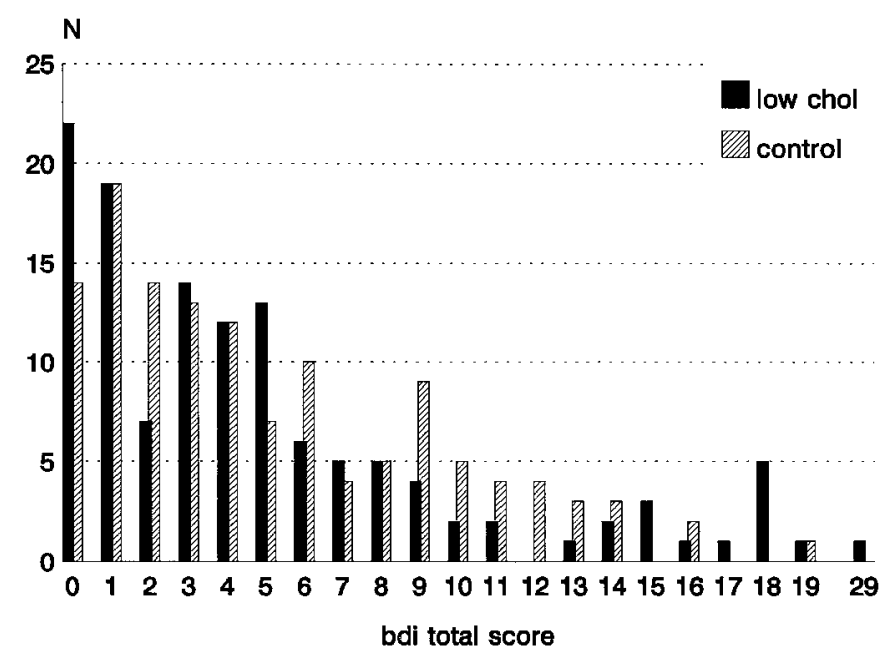

Fig. 1. Distribution of BDI scores in men with low cholesterol levels ( $\leq 4.5 \mathrm{mmol} / \mathrm{liter}$ ) compared with a reference group of men with cholesterol levels between 6 and $7 \mathrm{mmol} / \mathrm{liter}$.

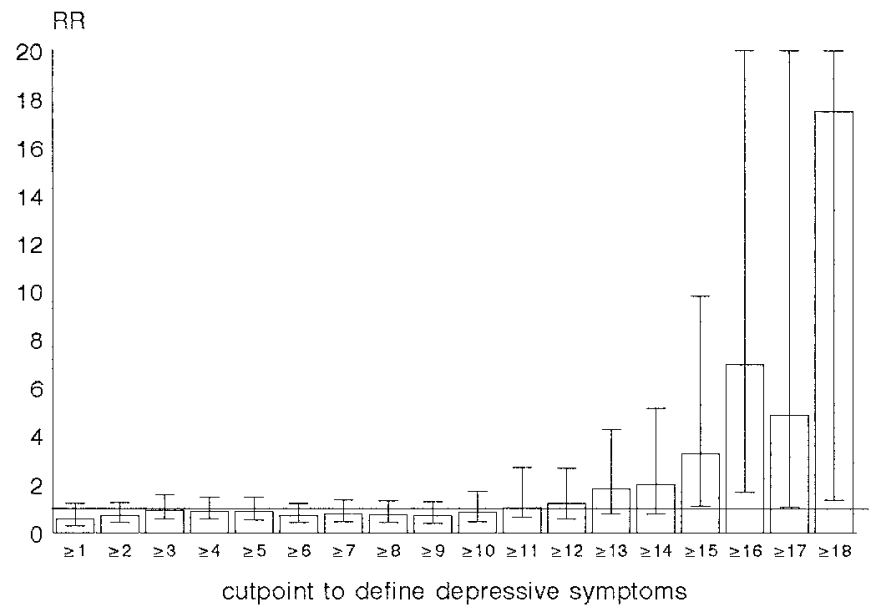

Fig. 2. Unadjusted RR of having depressive symptoms according to the BDI (with various cutoff points) in men with low cholesterol levels ( $\leq 4.5 \mathrm{mmol} / \mathrm{liter}$ ) compared with a reference group of men with cholesterol levels between 6 and 7 mmol/liter.

tion of the scores on these questionnaires did not reveal any relevant differences between the low cholesterol and reference groups.

The Anger-In and Anger-Out subscales of the SECQ showed a positive association with serum triglyceride levels (both subscales, $p=.003$ ). No associations were observed between triglyceride levels and scores on the other psychological questionnaires.

\section{DISCUSSION}

In our study among men aged 40 to 70 years, we observed a four- to seven-fold increased risk of severe depressive symptoms (defined as a score of $\geq 15$ on the BDI) among men with a chronically low cholesterol level ( $\leq 4.5 \mathrm{mmol} /$ liter $)$ compared with subjects in a reference group with a cholesterol level between 6 and $7 \mathrm{mmol} /$ liter. No clear differences were found in measures of anger, hostility, or impulsivity.

In a similar study $(N=1020)$, Morgan et al. (21) found a significantly higher risk of severe depressive symptoms (BDI score $\geq 13$ ) among elderly men $(\geq 70$ years, $N=394)$ with a low cholesterol level $(<4.14$ $\mathrm{mmol} / \mathrm{liter}$; mean not reported) compared with those with a higher cholesterol level $(\geq 4.14 \mathrm{mmol} / \mathrm{liter}$; mean not reported).

Brown et al. (22) used the CES-D in men and women aged 71 years or more $(N=3939$; men, $N=1434)$. Only in subjects aged 80 or more years were depressive symptoms more common in those with a low cholesterol level $(<4.14 \mathrm{mmol} /$ liter; mean not reported) than in those with a cholesterol level of $\geq 4.14 \mathrm{mmol} /$ liter (mean not reported). However, after multivariate adjustment for self-reported health, physical function, 
TABLE 2. Psychological Questionnaires Used in the Study and Median and Mean Values Measured in Men With a Low Cholesterol Level ( $\leq 4.5 \mathrm{mmol} / \mathrm{liter}$ ) and a Reference Group of Men With a Cholesterol Level Between 6 and $7 \mathrm{mmol} / \mathrm{liter}$

\begin{tabular}{|c|c|c|c|c|c|c|}
\hline \multirow[b]{2}{*}{ Questionnaire } & \multirow{2}{*}{$\begin{array}{l}\text { Score } \\
\text { Range }\end{array}$} & \multicolumn{2}{|c|}{ Median } & \multicolumn{2}{|c|}{ Mean } & \multirow[b]{2}{*}{$\mathrm{p}^{a}$} \\
\hline & & $\begin{array}{c}\text { Low Cholesterol } \\
\text { Group }\end{array}$ & $\begin{array}{c}\text { Reference } \\
\text { Group }\end{array}$ & $\begin{array}{c}\text { Low Cholesterol } \\
\text { Group }\end{array}$ & $\begin{array}{l}\text { Reference } \\
\text { Group }\end{array}$ & \\
\hline BDI (depression) (34) & $0-63$ & 4 & 4 & 5.0 & 5.1 & 0.37 \\
\hline \multicolumn{7}{|l|}{ SECQ (anger) (35) } \\
\hline Control Anger-In & $10-40$ & 31 & 33 & 30.9 & 31.4 & 0.27 \\
\hline Control Anger-Out & $10-40$ & 33 & 34 & 31.7 & 32.6 & 0.28 \\
\hline Anger-In & $10-40$ & 20 & 19 & 20.1 & 19.9 & 0.60 \\
\hline Anger-Out & $10-40$ & 16 & 17 & 17.0 & 18.0 & 0.19 \\
\hline \multicolumn{7}{|l|}{ BDHI (hostility) (38) } \\
\hline Assault & $0-20$ & 5 & 6 & 5.4 & 6.0 & 0.43 \\
\hline Indirect Hostility & $0-18$ & 4 & 4 & 4.2 & 3.9 & 0.46 \\
\hline Irritability & $0-22$ & 8 & 8 & 7.9 & 7.7 & 0.79 \\
\hline Negativism & $0-10$ & 5 & 5 & 5.1 & 5.2 & 0.52 \\
\hline Resentment & $0-16$ & 2 & 2 & 3.6 & 3.2 & 0.58 \\
\hline Suspicion & $0-20$ & 6 & 6 & 6.2 & 5.9 & 0.57 \\
\hline Verbal Hostility & $0-26$ & 12.5 & 13 & 12.3 & 13.2 & 0.20 \\
\hline Guilt & $0-18$ & 9 & 8 & 9.1 & 8.7 & 0.29 \\
\hline \multicolumn{7}{|l|}{ SAQ (anger) (37) } \\
\hline Anger-State & $10-40$ & 10 & 10 & 10.9 & 10.6 & 0.27 \\
\hline Anger-Trait & $10-40$ & 14 & 13 & 14.7 & 14.8 & 0.87 \\
\hline \multicolumn{7}{|l|}{ IMP (impulsivity) (39) } \\
\hline Trait & $11-44$ & 17 & 17 & 17.8 & 17.5 & 0.30 \\
\hline State & $14-56$ & 17 & 17 & 19.0 & 18.5 & 0.38 \\
\hline
\end{tabular}

${ }^{a}$ Nonparametric.

and number of medications used, this relationship weakened markedly. The BDI and the CES-D may differ in their ability to identify depression, although Zich et al. (44) indicated that the CES-D and BDI perform similarly as screening instruments for depression.

Associations between low cholesterol levels and depressive symptoms were observed in the higher age categories and not in the younger age categories in the studies by Brown et al. (22) (subjects $>70$ years old) and Morgan et al. (21) (subjects $\geq 80$ years old). We, however, observed the same association in younger age categories. More recently, both cross-sectional and longitudinal associations between cholesterol levels and measures of depression, hostility, and anger were assessed in young adults, aged 23 to 35 years, by Markowitz et al. (45). Their study included 4240 participants, of which 1041 were white men. Depressive symptoms were measured using the CES-D, hostility was measured with the Cook-Medley Hostility Scale, and anger was measured by means of the Spielberger Trait Anxiety Scale and the Anger-In subscale of the Spielberger Anger Expression Scale. In the cross-sectional analysis, no differences in depression, hostility, or anger scores were observed between those with a low cholesterol level (defined as the lowest $10 \%$ in white men, ie, $\leq 3.62 \mathrm{mmol} / \mathrm{liter}$ ) and those with higher cholesterol levels ( $\geq 3.62 \mathrm{mmol} /$ liter), even after adjustments for relevant covariates. In contrast to our study, a comparison of those with the lowest cholesterol levels with a group with substantially higher cholesterol levels (eg, around the 50th centile) was not included. Importantly, this study involved a relatively young group of men compared with prior studies, including our own, in which an association between lipid levels and depressive symptoms was observed.

Studies investigating associations between lipid levels and depressive symptoms are scarce. In an investigation among Swedish women, those with a low cholesterol level ( $\leq 4.7 \mathrm{mmol} / \mathrm{liter}$ ) had a statistically significantly higher prevalence of depressive symptoms, even after adjustment for various other variables, including alcohol consumption, body mass index, and age (46).

Although the cutoff points we used to define severe depressive symptoms (15 and 17) are frequently used in other studies, they remain rather arbitrary. Additional analyses using other cutoff points to classify depressive symptoms did not change our findings. Thus, the observed association between low cholesterol levels and depressive symptoms cannot be attributed to the few subjects with very high depression scores. In addition, exclusion of the two participants with the highest BDI score (both in the low cholesterol 
group) did not appreciably alter our findings, although the CI widened (without including 1.0).

The refusal of subjects to visit the research center for the second cholesterol measurement is unlikely to have introduced selection bias. First, the population included in the cholesterol screening survey was relatively healthy. Second, and more importantly, willingness to participate is not related to cholesterol level.

Alcohol intake was considerably lower in the low cholesterol group than in the reference group. Although our study design did not allow comparison of alcohol intake between depressed and nondepressed subjects, our findings seem to contradict the finding of higher alcohol intake in subjects with higher depression scores reported in other studies (47).

In contrast to Morgan et al. (21) and Brown et al. (22), we did not adjust for self-rated health or physical functioning in the multivariate analysis. In our view, adjustment for these factors in a multivariate analysis can be criticized because these factors may very well be part of the causal pathway relating cholesterol to depressive symptoms; therefore, adjustment could dilute a true, existing association. However, adjustment for the presence of chronic diseases (mainly gastrointestinal disorders) did not materially change the findings. Food pattern and changes in food pattern as potential confounders in the relationship between a low cholesterol level and depressive symptoms were not investigated in the two previous studies. Adjustment for caloric intake in the analyses, although including this variable in the analysis could equally be criticized, did not change the association between a low cholesterol level and depressive symptoms. Moreover, none of the participants reported major changes in food pattern over the last 5 years.

Fowkes et al. (11) examined the relationship between serum cholesterol level, triglyceride level, and aggression in the general population. In their study, the Bedford-Foulds Personality Deviance Questionnaire was used. Serum triglyceride levels were positively associated with hostile acts and domineering attitudes in men, independent of age, total and highdensity lipoprotein cholesterol, cigarette smoking, and alcohol consumption. Our finding of a positive association between serum triglyceride levels and the anger-in and anger-out scores on the SECQ seems to confirm the findings of Fowkes et al., although the Anger-In and Anger-Out subscales we used may not be completely equivalent to the Domineering Attitude and Hostile Acts subscales of the Bedford-Foulds Personality Deviance Questionnaire. The Anger-Trait subscale of the SAQ did not show any relationship with triglyceride levels. The mechanisms underlying the correlation between triglyceride level and anger remain to be established, although some investigators have suggested that aggressive behavior may lead to increased triglyceride levels, mediated by enhanced sympathetic drive (48). In another study, which investigated the relationship between lipid levels and anger in 18- to 30-year-old men, no significant associations between total serum cholesterol level and Anger-In and Anger-Out subscales were observed, but a statistically significant positive correlation between highdensity lipoprotein cholesterol and scores on an Anger-Out subscale of the Spielberger Anger Expression Scale $(p=.02)$ was present (15). We could not reproduce this finding in our study (data not shown).

We did not observe clear differences in hostility and aggression between the low cholesterol group and the reference group. In one other study, various types of hostility, including those measured by subscales of the BDHI (14) and expressive hostility (ie, the sum score of the Assault, Verbal, and Indirect Hostility subscales), were shown to have a significant positive association with both total cholesterol and low-density lipoprotein cholesterol levels. We could not confirm this finding, partly because of the lack of participants with high cholesterol levels in our study.

Although impulsivity is thought to be associated with aggression and depression, low cholesterol levels and impulsivity measured with the adapted version of Eysenck and Eysenck's (39) questionnaire were not related in our study. We could not identify other studies assessing the association between cholesterol level and impulsivity. This might be due to the lack of generally used, reliable questionnaires to assess impulsivity.

It is still unclear how cholesterol levels could influence the occurrence of depressive symptoms. It has been proposed that changes in the serotonin metabolism of the central nervous system, through decreased availability of the serotonin precursor tryptophan, is involved in this process $(7,8,16,17)$. The decreased availability of tryptophan to the brain may be induced by an increased binding of this amino acid to albumin, resulting from a reduction in binding of fatty acids (fatty acids compete with tryptophan for binding to albumin). This reduction of binding of fatty acids to albumin is thought to be related to low cholesterol levels.

One should keep in mind the essential difference between a naturally occurring low cholesterol level and a lowered cholesterol level and the consequences of each. A naturally occurring low cholesterol level is considered a life-long existing feature, whereas a lowered cholesterol level is attained by dietary or drug intervention. Although the prevalence of depressive 
symptoms is not always assessed in cholesterol-lowering trials, these studies have not shown an excess of deaths due to suicide or accidents in the study medication group $(27,28)$. One randomized, placebo-controlled study showed no difference of effect on mood (as measured by a shortened profile of mood states questionnaire or reported use of psychotropic medication) between patients using simvastatin and those receiving placebo (49).

In conclusion, we observed an increased prevalence of severe depressive symptoms among men with a low serum cholesterol level. This may be an important finding in the ongoing debate concerning the putative association between low cholesterol levels and death due to violent causes. Future studies are needed to reveal the mechanisms of this increased risk and to demonstrate its causal association with chronically low cholesterol levels.

This study was supported by Grant 28-2349 from the Netherlands Prevention Fund and by grants from the Rotterdam Medical Research Foundation.

\section{REFERENCES}

1. Pekkanen J, Nissinen A, Punsar S, Karvonen MJ. Serum cholesterol and risk of accidental or violent death in a 25 year followup: the Finnish cohorts of the Seven Countries Study. Arch Intern Med 1989;149:1589-91.

2. Chen Z, Peto R, Collins R, MacMahon S, Lu J, Li W. Serum cholesterol concentration and coronary heart disease in a population with low cholesterol concentrations. BMJ 1991;303: $276-82$.

3. Davey Smith G, Shipley MJ, Marmot MG, Rose G. Plasma cholesterol concentration and mortality: the Whitehall Study. JAMA 1992;267:70-6.

4. Neaton JD, Blackburn H, Jacobs D, Kuller L, Lee D-J, Sherwin R, Shih J, Stamler J, Wentworth D, Multiple Risk Intervention Trial Research Group. Serum cholesterol level and mortality findings for men screened in the Multiple Risk Factor Intervention Trial. Arch Intern Med 1992;152:1490-500.

5. Lindberg G, Rastam L, Gullberg B, Eklund GA. Low serum cholesterol concentration and short-term mortality from injuries in men and women. BMJ 1992;305:277-9.

6. Zureik M, Courbon D, Ducimetiere P. Serum cholesterol concentrations and death from suicide in men: Paris prospective study I. BMJ 1996;313:649-51.

7. Engelberg H. Low serum cholesterol and suicide. Lancet 1992; 339:727-9.

8. Salter M. Lower serum cholesterol and suicide [letter]. Lancet 1992;339:1169.

9. Steegmans PHA, Bak AAA, van der Does E, Grobbee DE, Hoes AW. Low serum cholesterol, violent death and serotonin metabolism: a review. Cardiovasc Risk Factors 1995;5:267-80.

10. Steegmans PHA, Fekkes D, Hoes AW, Bak AAA, van der Does E, Grobbee DE. Low serum cholesterol concentration and serotonin metabolism in men. BMJ 1996;312:221.

11. Fowkes FGR, Leng GC, Donnan PT, Deary IJ, Riemersma RA, Housley E. Serum cholesterol, triglycerides, and aggression in the general population. Lancet 1992;340:995-8.
12. Hillbrand M, Foster HG. Serum cholesterol levels and severity of aggression. Psychol Rep 1993;72:270.

13. Spitz RT, Hillbrand M, Foster HG. Serum cholesterol levels and frequency of aggression. Psychol Rep 1994;74:622.

14. Dujovne VF, Houston BK. Hostility-related variables and plasma lipid levels. J Behav Med 1991;14:555-65.

15. Waldstein SR, Polefrone JM, Bachen EA, Muldoon MF, Kaplan JR, Manuck SB. Relationship of cardiovascular reactivity and anger expression to serum lipid concentrations in healthy young men. J Psychosom Res 1993;37:249-56.

16. Kaplan JR, Shively CA, Fontenot MB, Morgan TM, Howell SM, Manuck SB, Muldoon MF, Mann JJ. Demonstration of an association among dietary cholesterol, central serotonergic activity, and social behavior in monkeys. Psychosom Med 1994;56: 479-84.

17. Fontenot MB, Kaplan JR, Sively CA, Manuck SB, Mann JJ. Cholesterol, serotonin, and behavior in young monkeys. Ann N Y Acad Sci 1996;794:352-4.

18. Åsberg M, Schalling D, Träksmann-Bendz, Wägner A. Psychobiology of suicide, impulsivity, and related phenomena. In: Meltzer HY, editor. Psychopharmacology: third generation of progress. New York: Raven Press; 1987. p. 655-88.

19. Roy A, Linnoila M. Suicidal behavior, impulsiveness and serotonin. Acta Psychiatr Scand 1988;78:529-35.

20. Coccaro EF. Central serotonin and impulsive aggression. $\mathrm{Br} \mathrm{J}$ Psychiatry 1989;155(Suppl 8):52-62.

21. Morgan RE, Palinkas LA, Barrett-Connor EL, Wingard DL. Plasma cholesterol and depressive symptoms in older men. Lancet 1993;341:75-9.

22. Brown SL, Salive ME, Harris TB, Simonsick EM, Guralnick JM, Kohout FJ. Low cholesterol concentrations and severe depressive symptoms in elderly people. BMJ 1994;308:1328-32.

23. Dayton S, Pearce ML, Hashimoto S, Dixon WJ, Tomiyasu U. A controlled clinical trial of a diet high in unsaturated fat in preventing complications of atherosclerosis. Circulation 1969; 40(Suppl II):1-62.

24. Frantz ID Jr, Dawson EA, Ashman PL, Gatewood LC, Bartsch GE, Kuba K, Brewer ER. Test of effect of lipid lowering by diet on cardiovascular risk: the Minnesota Coronary Survey. Arteriosclerosis 1989;9:129-35.

25. Lipid Research Clinics Program. The Lipid Research Clinics Primary Prevention Trial results. I. Reduction in incidence of coronary heart disease. JAMA 1984;251:351-64.

26. Frick MH, Elo O, Haapa K, Heinonen OP, Heinsalmi P, Helo P, Huttunen JK, Kaitaniemi P, Koskinen P, Manninen V, Mäenpää H, Mälkönen M, Mänttäri M, Norola S, Pasternack A, Pikkarainen J, Romo M, Sjöblom T, Nikkilä EA. Helsinki Heart Study: primary prevention trial with gemfibrozil in middle-aged men with dyslipidemia. N Engl J Med 1987;317:1237-45.

27. Scandinavian Simvastatin Survival Study Group. Randomised trial of cholesterol lowering in 4444 patients with coronary heart disease: the Scandinavian Simvastatin Survival Study (4S). Lancet 1994;334:1383-9.

28. Shepherd J, Cobbe SM, Ford I, Isles CG, Lorimer AR, MacFarlane PW, McKillop JH, Packard CJ, West of Scotland Coronary Prevention Study Group. Prevention of coronary heart diseases with pravastatin in men with hypercholesterolemia. N Engl J Med 1995;333:1301-7.

29. Duits N, Bos FM. Depressive symptoms and cholesterollowering drugs [letter]. Lancet 1993;341:114.

30. Lechleitner M, Hoppichler F, Konwalinka G, Patsch JR, Braunsteiner H. Depressive symptoms in hypercholesterolaemic patients treated with pravastatin [letter]. Lancet 1992;340:910.

31. Weidner G, Connor SL, Hollis JF, Connor WE. Improvements in 
hostility and depression in relation to dietary change and cholesterol lowering: the Family Heart Study. Ann Intern Med 1992; 117:820-3.

32. van Gent CM, van der Voort HA, de Bruijn AM, Klein F. Cholesterol determinations: a comparative study of methods with special reference to enzymatic procedures. Clin Chim Acta 1977;75:243-51.

33. Goldbohm RA, van den Brandt PA, Brants HAM, van't Veer P, Sturmans F, Hermus JJ. Validation of a dietary questionnaire used in a large-scale prospective cohort study on diet and cancer. Eur J Clin Nutr 1994;48:253-65.

34. Beck AT, Ward CH, Mendelson M, Mock J, Erbaugh J. An inventory for measuring depression. Arch Gen Psychiatry 1961;4:561-71.

35. Maes S, van Elderen T, van der Ploeg H, Spielberger C. Zelf expressie en controle vragenlijst. Lisse, The Netherlands: Swets \& Zeitlinger; 1987.

36. Spielberger CD, Johnson EH, Russell SF, Crane RJ, Jacobs GA, Worden TJ. The experience and expression of anger: construction and validation of an anger expression scale. In: Chesney MA, Rosenman RH, editors. Anger and hostility in cardiovascular and behavioral disorders. Washington DC: Hemisphere Publishing Corporation; 1985. p. 5-30.

37. van der Ploeg HM, Defares PB, Spielberger CD. Handleiding bij de Zelf Analyse Vragenlijst, ZAV. Lisse, The Netherlands: Swets \& Zeitlinger; 1982.

38. Buss AH, Durkee A. An inventory for assessing different kinds of hostility. J Consult Psychol 1957;21:343-9.

39. Eysenck SB, Eysenck HJ. The place of impulsiveness in a dimensional system of personality description. Br J Soc Clin Psychol 1977;16:57-68.
40. Beck AT, Steer RA. Beck Depression Inventory manual. New York: Psychological Corporation; 1987.

41. Bendig AW. Factor analytic scales of covert and overt hostility. J Consult Psychol 1962;26:200-12.

42. Musante L, MacDougall JM, Dembrowski TM, Costa PT. Potential for hostility and dimensions of anger. Health Psychol 1989; 8:343-54.

43. Bushman BJ, Cooper HM, Lemke KM. Meta-analysis of factor analyses: an illustration using the Buss-Durkee Hostility Inventory. Pers Soc Psychol Bull 1991;17:344-9.

44. Zich JM, Attkisson CC, Greenfield CC. Screening for depression in primary care clinics: the CES-D and the BDI. Int J Psychiatry Med 1990;20:259-77.

45. Markowitz JH, Smith D, Raczynski JM, Oberman A, Williams OD, Knox S, Jacobs DR. Lack of relations of hostility, negative affect, and high-risk behavior with low plasma lipid levels in the Coronary Artery Risk Development in Young Adults Study. Arch Intern Med 1997;157:1953-9.

46. Horsten M, Wamala SP, Vingerhoets A, Orth-Gomer K. Depressive symptoms, social support, and lipid profile in healthy middle-aged women. Psychosom Med 1997;59:521-8.

47. Neff JA. Alcohol consumption and psychological distress. Alcohol Alcohol 1986;21:111-9.

48. Sugden PH. Serum cholesterol, triglycerides, and aggression [letter]. Lancet 1992;340:1350.

49. Wardle J, Armitage J, Collins R, Wallendszus K, Keech A, Lawson A, Oxford Cholesterol Study Group. Randomised placebo controlled trial of effect on mood of lowering cholesterol concentration. BMJ 1996;313:75-8.

\section{Postdoctoral Training Program in Behavioral Medicine University of California, San Diego}

UCSD is pleased to announce a new Postdoctoral Fellowship Program for PhDs or MDs with an interest in behavioral medicine research. The program emphasizes research excellence in cardiovascular behavioral medicine, psychoneuroimmunology, sleep, psycho-oncology, HIV, and health policy research. Each fellow will have a primary laboratory placement in one of the following investigators' laboratories: Sonia AncoliIsrael, PhD, Joel E. Dimsdale, MD, Igor Grant, MD, Michael Irwin, MD, Robert Kaplan, PhD, Paul Mills, PhD. In addition to the laboratory placement, fellows will participate in an extensive array of on-going research seminars as well as special seminars in statistics, epidemiology, assay technique, ethics of investigational studies, and career development.

Interested applicants should contact: Joel E. Dimsdale, MD, Department of Psychiatry—0804, 9500 Gilman Drive, La Jolla, CA 92093-0804, with a copy of their resume, a one-page letter detailing career goals-research interests and desired laboratory placement. In addition, applicants should ask two individuals to forward a letter of recommendation to Dr. Dimsdale. Application deadline is May 15, 2000. UCSD is an equal opportunity employer. 